\title{
Development of a Graphene-Based Aptamer Sensor for Electrochemical Detection of Serum ECP Levels
}

\author{
Zhitao Wang ${ }^{1}$, Jun Yang ${ }^{2}$ and Lin Gui ${ }^{3 *}$ \\ ${ }^{1}$ Department of Pediatrics, Wuchang Hospital, Wuhan, Hubei, 430063, P.R. China \\ ${ }^{2}$ Department of Pediatrics, Xiangaoxin Hospital, Xian, Shanxi, 710075, P.R. China \\ ${ }^{3}$ Department of Paediatrics, Maternal and Child Health Hospital of Hubei Province, Wuhan, Hubei, \\ 430070, P. R. China \\ *E-mail: guilin_vivi@163.com
}

doi: $10.20964 / 2017.10 .54$

Received: 17 June 2017 / Accepted: 11 August 2017 / Published: 12 September 2017

The eosinophil cationic protein (ECP) is the biological marker for bronchial eosinophil inflammation, and it can be detected in serological levels to objectively predict the activity and severity of asthma in children. This work reports a facile electrochemical aptasensor without labels for the detection of ECP using a glassy carbon electrode (GCE) modified by $\mathrm{Au}$ nanoparticles dotted with a graphene (GNPs/GR) nanocomposite film. The ECP-aptamer interactions were studied using ferricyanide as the electrochemical probe. The terminal GNPs/GR layer displayed an acceptable current for ECP determination. The peak current variation of ferricyanide was linearly related to the ECP concentration $(0.01 \mu \mathrm{M}-10 \mu \mathrm{M})$, and the limit of detection (LOD) was $4 \mathrm{nM}$.

Keywords: Eosinophil cationic protein; Aptamer sensor; Graphene; Electrochemical determination; Children asthmatic attack

\section{FULL TEXT}

(C) 2017 The Authors. Published by ESG (www.electrochemsci.org). This article is an open access article distributed under the terms and conditions of the Creative Commons Attribution license (http://creativecommons.org/licenses/by/4.0/). 